\title{
Richard Schantz
}

\section{WAS TARSKI A DEFLATIONIST?}

\begin{abstract}
The article explores the relationship between Tarski's theory of truth and modern deflationary or minimalist accounts of truth. The author notes many similarites, but he also identifies an important difference between Tarski's theory and the various approaches of his modern followers: Tarski thought of his theory of truth as an elaboration of the classical correspondence notion. The heart of his theory is the definition of truth in terms of satisfaction. Truth is explicated in terms of a relation between language and aspects of external reality. It is just this central component of his theory which is rejected by modern deflationism and minimalism.
\end{abstract}


A currently very popular view about truth is the so-called "deflationist" conception of truth. There are various brands of deflationism: there are Gottlob Frege's, Frank Ramsey's and Peter Strawson's versions of the redundancy theory of truth, there is the "prosentential" theory of Dorothy Grover, Nuel Belnap and John Camp, there is the disquotationalist account advocated by Alfred Ayer, W. V. Quine, Richard Rorty, Stephen Leeds, Scott Soames and Michael Williams, and there is last but not least Paul Horwich's "minimalism". ${ }^{1}$ What all these various deflationary views have in common is their conviction that what has come to be called substantive or robust theories of truth - such as correspondence or coherence or pragmatic theories - are all on the wrong track. According to deflationism, substantive theories share the assumption that truth has a nature, a nature which can be analyzed in epistemic or semantical or metaphysical terms. Deflationists reject this assumption. Truth, they urge, has no nature. The concept of truth does not express an interesting property or an interesting relation. Consequently, it should not be given a central place in our philosophical reflections. Rather, truth is a purely formal or logical concept whose correct explanation requires far less extravagant conceptual resources than the proponents of substantive theories suppose. The ambitious aim of deflationism is to deflate the overinflated theories developed by their substantivist opponents.

Let us start looking at the disquotational account which is surely the most prominent deflationary view on the contemporary scene. The general idea on which it is based is that a sentence of the form " $s$ is true" has the same meaning or the same cognitive content as the sentence $s$. So, according to this theory, the two sentences "Snow is white" is true" and "Snow is white" are semantically equivalent or convey essentially the same information. But what exactly does "disquotation" mean? Let us keep to Quine upon whose canonical formulations most adherents of this conception implicitly or explicitly fall back. Quine says:

\footnotetext{
${ }^{1}$ See Frege 1892; Ramsey 1927; Strawson 1949; Grover, Belnap, Camp 1975; Grover 1992; Ayer 1936; Quine 1970, 1987, 1990; Rorty 1986; Leeds 1978, Soames 1984; Williams 1986; Horwich 1990.
} 
The truth predicate is a reminder that, despite a technical ascent to talk of sentences, our eye is on the world. This cancellatory force of the truth predicate is explicit in Tarski's paradigm:

"Snow is white" is true if and only if snow is white.

Quotation marks make all the difference between talking about words and talking about snow. The quotation is a name of a sentence that contains a name, namely "snow", of snow. By calling the sentence true, we call snow white. The truth predicate is a device of disquotation. (Quine 1970, 12)

Quine approaches truth from considerations about the function of the truth predicate. The term "true" is a device for semantical ascent and semantical descent. If we go up one level and attribute truth to the sentence "Snow is white", then we attribute whiteness to snow. The truth predicate enables us to return from the level of talk about language to the level of talk about the world. The use of "true" signalizes that, though a sentence is mentioned, and we are thus operating on a linguistic plane of reference, our interest is nevertheless not directed on language but on extralinguistic reality. The ascription of truth, as it were, sweeps away the quotation marks, producing a sentence suitable for saying that snow is white. In other words, it is the function of "true" to cancel the effect of semantic ascent. That is why Quine says quite succintly: "Truth is disquotation" (Quine 1990, 80).

So the truth predicate seems to be superfluous when it is applied to a particular sentence because we could just as well use that very sentence. As Quine puts it:

So long as we are speaking only about the truth of singly given sentences, the perfect theory of truth is what Sellars has called the disappearance theory of truth. (Quine 1970, 11)

Disquotationalists typically concede, however, that the term "true" is not exclusively used in connection with explicitly given sentences, that is, with sentences in quotation marks; it also occurs in other types of contexts. But, if that is the case, the simple disquotational device by itself does not enable us to eliminate the truth predicate from all contexts in which it occurs. Therefore, a strict disquotational account is not general enough and must be supplemented somehow. Deflationists usually maintain that the truth predicate shows its special utility or importance just in those contexts where certain technical complications compel us to mention sentences instead of directly talking about the world. 
It was Tarski who first saw the limits of the simple kind of elimination. ${ }^{2}$ He saw that it cannot be made, firstly, in the case of universal sentences which express the fact that all sentences of such and such a type are true or are not true, as for example in the sentence "All consequences of true sentences are true"; and, secondly, in those cases of particular sentences of the form " $s$ is true" in which the reference to the sentence which is said to be true occurs in a form that does not enable us to reconstruct the sentence itself, as in the sentence "The first sentence written by Plato is true".

Following Tarski, disquotationalists stress that the truth predicate is required primarily in those cases in which we want to generalize with respect to sentence positions. We need "true" for saying in general that every sentence that has a certain form is true; or in deductive logic, to justify rules of inference, that is, to be able to say that in every inference of a certain kind truth is transmitted from the premisses to the conclusion. The utility of the truth predicate is said to lie in its providing for a way of generalizing with respect to sentence positions. "True" is in the end merely a surrogate for infinite conjunctions and infinite disjunctions. If our language allowed the expression of infinite conjunctions and infinite disjunctions, the truth predicate would lose its most important function. ${ }^{3}$ So the truth predicate is not merely a device for disquotation; it is also a device for expressing or abbreviating infinite conjunctions and disjunctions by finite means.

It should be clear, then, that the disquotational account does not define truth, at least not in the strict sense of "definition" which requires the elimination of the defined expression from every context in which it can occur. It only tells us how to eliminate the truth predicate when it is attached to a quotation. Some disquotationalists leave it at that. Others, above all Quine, of course, want a genuine, an explicit definition of truth and to that end turn to Tarski. But even those proponents of disquotationalism who are not convinced that a satisfactory specification of the meaning or the use of a predicate must take the form of an eliminative definition connect their accounts in one way or another to Tarski's work.

\section{II}

We all know that it was Tarski's prime aim to show that the concept of truth, if it is carefully employed, is a consistent concept, a concept which does not

\footnotetext{
2 Tarski 1944, 358-359.

${ }^{3}$ Leeds 1978, 121.
} 
involve us in semantical paradoxes. Therefrom resulted his project to provide an exact definition of truth, a definition which must fulfill two conditions: firstly, it must be "materially adequate", and secondly, it must be "formally correct". The first of these conditions restricts the possible content, the second the possible form, of any acceptable definition. To fulfill the material adequacy condition Tarski introduces his famous Convention T: An acceptable definition of truth for a language must have among its consequences all instances of the following schema:

$$
s \text { is true if and only if } p
$$

where " $s$ " is to be replaced by a standardized name of any sentence of the object language, the language for which truth is being defined, and " $p$ " is to be replaced by that same sentence or its translation, depending on whether or not the object language is contained in the metalanguage as a proper part. To use Tarski's example, an instance of this schema would be:

"Snow is white" is true if and only if snow is white.

Tarski calls every equivalence of form T a "partial definition of truth", which explains, as he says, what the truth of the individual sentence mentioned consists in. And he often characterizes his project as providing a definition equivalent to the logical conjunction of all such instances of $\mathrm{T}$, all such "T-sentences" as they are usually called nowadays, for the language under study. Indeed, Tarski mentions that if the language consisted of only a finite number of sentences, Convention $\mathrm{T}$ could be satisfied by a definition that simply listed a T-sentence for each sentence in the language. But any interesting language has a potential infinity of sentences; for such a language a list-like definition cannot be given. We cannot compile an infinite list. For such languages the definition must take another form.

In the case of languages whose only complex sentences are truth functions of their components, it is possible to define truth for complex sentences directly in terms of truth for elementary sentences. With languages with quantificational structure, however, this direct method founders, since the components of complex sentences are no longer themselves necessarily sentences. The use of variables, which is necessary for quantificational languages, has the consequence that open sentences and value assignments to free variables must be taken into account. In such languages, complex sentences may be produced from open sentences by binding the variables occurring in them. It is the most distinctive feature of Tarski's definition of truth that he ingeniously solved this problem with the concept of sat- 
isfaction. Satisfaction is a relation between sentences, open or closed, and infinite sequences of objects which belong to the range of variables of the language. Since, in the case of quantificational languages, sentence-forming operations operate on closed as well as open sentences, it is not possible to give a recursive definition of truth itself. The essential idea of Tarski's solution is to take a roundabout course: he first constructs a recursive definition of satisfaction, and then he defines truth on that basis. Just as closed sentences are limiting cases of open sentences, so truth is a limiting case of satisfaction. Accordingly, Tarski defines a sentence as true just in case it is satisfied by all sequences of objects. With the technical resources of set theory, the recursive definition can, finally, be converted into an explicit or eliminative definition.

\section{III}

We have seen that deflationists usually rely in one way or another on Tarski's formal work. But is his approach to truth really deflationary? It might seem so. Deflationists can indeed claim that, by means of his truth characterizations, we can show that a sentence of the form " $s$ is true" is provably equivalent to the simple sentence $s$. And as concerns those contexts in which "true" is not applied to a sentence quoted, but predicated of whole classes of sentences, it can be regarded, from the perspective of deflationism, as Tarski's great merit to have shown how the truth predicate can be dispensed with. After all, it has been explicitly defined by him.

Further, the deflationists can apparently appeal to Tarski in support of their distinctive claim that the concept of truth is an epistemologically and metaphysically completely neutral concept. It has, so they assert, neither anything to do with the nature and justification of knowledge nor with the grand metaphysical debate between realism and idealism. The hope for an epistemic or metaphysical analysis of truth must be abandoned once and for all. Tarski seems to be in agreement with them, when he says:

In fact, the semantic definition of truth implies nothing regarding the conditions under which a sentence like (1):

snow is white

can be asserted. It implies only that, whenever we assert or reject this sentence, we must be ready to assert or reject the correlated sentence (2):

(2) the sentence "snow is white" is true. 
Thus, we may accept the semantic conception of truth without giving up any epistemological attitude we may have had; we may remain naive realists, critical realists or idealists, empiricists or metaphysicians whatever we were before. The semantic conception is completely neutral toward all these issues. (Tarski 1944, 361-362)

The epistemological and metaphysical neutrality of Tarski's theory is for many philosophers a stone of contention. But not so for deflationists who, on the contrary, give strong applause to this neutrality. Soames, for example, says:

What does seem right about Tarski's approach is its deflationist character. [...] Truth is a useful notion, but it is not the key to what there is, or to how we represent the world to ourselves through language. (Soames 1984, 429)

And Leeds takes the same line, when he remarks:

Truth is useful, we may say, as a device of (what Quine calls) disquotation. [...] To explain the utility of disquotation, we need say nothing about the relations between language and the world. (Leeds 1978, 122)

So was Tarski a deflationist? In spite of the many similarities, which in fact there are between their positions, I still take it to be a very difficult question. For there are also some differences which must not be underestimated. One important difference is that Tarski regarded his theory as an elaboration of the traditional correspondence theory of truth. In "The establishment of scientific semantics" he says:

We shall understand by semantics the totality of considerations concerning those concepts which, roughly speaking, express certain connexions between the expressions of a language and the objects and states of affairs referred to by these expressions. [...] The concept of truth also - and this is not commonly recognized — is to be included here, at least in its classical interpretation, according to which "true" signifies the same as "corresponding with reality". (Tarski 1956b, 401)

And again:

We regard the truth of a sentence as its "corresponding with reality". (Tarski 1956b, 404)

In "The semantic conception of truth" he tells us that he does not aim to assign a new meaning to an old world, but "to catch hold of the actual meaning of an old notion" (Tarski 1944, 341). He hopes his definition to do justice to the intuitions of the "classical Aristotelian conception of truth" (Tarski 1944, 342), as expressed in Aristotle's famous dictum: 
To say of what is that it is not, or of what is not that it is, is false, while to say of what is that it is, or of what is not that it is not, is true.

Tarski puts forward two further formulations:

The truth of a sentence consists in its agreement with (or correspondence to) reality.

And:

A sentence is true if it designates an existing state of affairs. (Tarski 1944, 343)

He regards none of these formulations as "sufficiently precise and clear", though he prefers the original Aristotelian characterization to the two others. In "The concept of truth in formalized languages" he expressed the semantical definition, informally, in the following words:

A true sentence is one which says that the state of affairs is so and so, and the state of affairs indeed is so and so. (Tarski 1956a, 155)

Of course, from the standpoint of precision and formal correctness this formulation is not yet satisfactory. But Tarski sees it as the prime task of a semantical definition to make the clear intuitive meaning of this formulation more precise and to give it a correct form.

In "Truth and proof", finally, he even identifies the classical conception with the semantical conception of truth, and he remarks that the correspondence theory is sometimes talked of as the theory which is based on the classical conception of truth. Tarski thinks that such expressions as "agreement" or "correspondence with reality" are vague and metaphorical. But he wants to preserve the correspondence intuition that a sentence which claims that things are so-and-so is true if and only if things really are so-and-so.

I want to characterize a correspondence theory, roughly, as a theory which explains truth by certain relations between linguistic expressions and extralinguistic entities, between language and reality. Donald Davidson, in his early article "True to the facts" (Davidson 1984, 37-54), and Hartry Field in "Quine and the correspondence theory" (Field 1974) have proposed quite similar characterizations. These characterizations are much more modest than classical attempts to explicate the idea of correspondence. Often it was simply said that a sentence or a proposition is true if and only if there is a fact which they mirror or picture. And sometimes even an isomorphism between the level of language or thought and the level of the world was postulated. The structure of a sentence or a belief was supposed to picture a fact in ways similar to the way in which a map pictures that part of the world that it is a picture of. 
Indeed, an adequate defence of a tenable form of the correspondence theory requires a specification both of the relation itself and of the linguistic and nonlinguistic relata that it is to combine with one another. However, traditional attempts to analyze the key concepts did not get beyond the use of metaphors. Facts or states of affairs, for example, were often introduced rather casually as entities with uncertain identity conditions. No wonder, then, that Tarski so emphatically insists upon making the notion of correspondence more precise.

In the sense of my characterization, which deliberately avoids the ontological category of fact, Tarski's theory is a correspondence theory because in it truth is explained in terms of satisfaction, and satisfaction is a relation between open sentences and objects which belong to the range of variables of those open sentences. Actually, it already follows from Tarski's own description of semantics as a theory of reference, i.e., as a discipline which deals with the referential relations between expressions and their referents, and from his classification of truth as a semantical concept, that he advocates a form of a correspondence theory of truth.

Some philosophers have asserted that Tarski's theory is a correspondence theory because it implies all equivalences T, all T-sentences. And indeed, a case can be made for a correspondence theoretical interpretation of these equivalences. According to them, the truth of a sentence depends on only two things: on their meaning, and on the way the world is. A T-sentence provides us with necessary and sufficient conditions for the truth of a sentence, and so explains what its truth consists in. What is the reason, so we can pointedly ask, for the truth of the sentence "Snow is white"? What makes this sentence true? Well, the reason for the truth of this sentence, what makes it true, is simply that the world is so arranged that snow is white. It is exactly because snow is white that the sentence "Snow is white" is true.

Even Quine says that T-sentences are the "significant residue" of the correspondence theory, ${ }^{4}$ that the "underlying validity" of the correspondence theory finds expression in T-sentences ${ }^{5}$ or that "truth consists in the world's being as the sentence says" ${ }^{6}$.

But we must take care, not to attach too much significance to such occasional remarks by Quine, which seem to point in the direction of a correspondence theory. For, on his view, T-sentences are the only thing

\footnotetext{
${ }^{4}$ Quine 1987, 213.

${ }^{5}$ Quine 1990, 80.

${ }^{6}$ Ibid., 81.
} 
that can in the end be saved from the correspondence theory. T-sentences preserve the strong intuition, on which the various versions of this theory are based, the intuition, that true statements agree with the world, or that it is the world which makes our statements true. Quine leaves no doubt that he categorically dismisses a correspondence theory that tries to go beyond the disquotational account of truth. The attempts to develop such a theory typically lead its adherents to postulate mysterious pseudoentities like facts, states of affairs or propositions devoid of any explanatory value.

Paul Horwich's attitude towards the correspondence theory seems to be a bit more conciliatory. He, too, is convinced that his "minimalist conception of truth" can accommodate the central intuition on which correspondence theories are based. He maintains:

The correspondence conception of truth involves two claims: (a) that truths correspond to reality; and (b) that such correspondence is what truth essentially is. And the minimalist response [...] is to concede the first of these theses but to deny the second. (Horwich 1990, 124)

What truth essentially is, is captured in the equivalence schema $\mathrm{T}$, or, since for Horwich - in contrast to Quine and, of course, to Tarski - propositions are the primary bearers of truth values, in the analogous schema "The proposition that $p$ is true if and only if $p$ ". Horwich's theory simply consists of all propositions of this form, of all equivalence axioms. He concedes that the theory cannot be explicitly formulated - owing to the infinity of the instances of his equivalence schema and owing to the inexpressibility of some propositions in any natural language. His basic theory of truth involves nothing more than the instances of the equivalence schema. We should neither expect nor desire a deeper explanation of why it is that the equivalence schema holds. ${ }^{7}$ The search for a finite body of general principles that explain the minimal theory is entirely futile. The propositions of the minimal theory are much too simple to require any explanation.

And yet, Horwich asserts that the minimal theory provides, in combination with theories of other phenomena, a satisfactory explanation of all facts involving truth. ${ }^{8}$ Moreover, the minimal theory is supposed to give an account of the meaning, and of our understanding, of the word "true" ${ }^{9}$ The meaning of "true" - its use in our language — is determined by our disposition to stipulate instances of the equivalence schema, and, correspondingly,

\footnotetext{
${ }^{7}$ Horwich 1990, 50-53.

8 Ibid., 7, 25-26.

${ }^{9}$ Ibid., 36-38.
} 
our understanding of "true" consists in our disposition to accept a priori, without evidence, any instantiation of this schema.

Horwich recognizes that the minimal theory does not yield an explicit, eliminative analysis of "true", one that permits us to eliminate "true" from every context in which it occurs. A satisfactory characterization of the meaning of "true", he insists, does not have to take the form of a specification of necessary and sufficient conditions for its correct application. Rather, he regards the minimal theory as an implicit or use definition of "true". ${ }^{10}$ As an illuminating example of a use definition, he mentions "the idea that our conception of number is determined by the disposition to accept Peano's axioms" ${ }^{11}$. Though his minimal theory of truth involves nothing more than the instances of the equivalence schema, Horwich is prepared to admit that truth has further properties. And he maintains that the property of corresponding to the world belongs to these further properties. His deflationary or minimalist position does not deny, then, that true propositions correspond to the world; it does not even deny that each true proposition is made true by the existence of a corresponding fact. ${ }^{12}$ All of these properties, so Horwich asserts confidently, are compatible with his minimalism.

What is not compatibel with his minimalism, however, is an explanation of truth in terms of correspondence or reference or satisfaction. There are, he claims, no constitutive relations between truth on the one hand and reference, satisfaction or correspondence on the other. ${ }^{13}$ It is a remarkable fact that, in this important respect, he distances himself so plainly from Tarski, for in Tarski's compositional approach truth is defined just in terms of satisfaction. Horwich explicitly reproaches theories in Tarski's style with being "unnecessarily complex" and with fostering the misleading impression that truth, reference and satisfaction are inextricably intertwined with one another. None of the deflationists has so pointedly dissociated himself from Tarski up to now. Truth, Horwich maintains, "has a certain purity", and by that he means that our understanding of truth is independent of those other notions. He does not want to deny that there are semantical principles relating those concepts, such as the principle:

" $a$ is $F$ " is true if and only if there exists an object $x$ such that " $a$ " refers to $x$ and " $F$ " is satisfied by $x$.

\footnotetext{
${ }^{10}$ Ibid., 34-37.

11 Ibid., 35.

${ }^{12}$ Ibid., 110-112.

13 Ibid., 117-120.
} 
But he does not treat such principles as explanatory basic. Instead, he proclaims that they should be derived from a conjunction of the theory of truth and separate minimalist theories of reference and satisfaction.

Thus, he subscribes to a full-fledged minimalism. Not only does he advocate a minimalist theory of truth, but also minimalist theories of reference and satisfaction. His theory of reference, for example, consists of axioms of the following form:

For all $x$, " $a$ " refers to $x$ if and only if $a=x$.

Reference and satisfaction, he argues, are just as much "in need of infinite, deflationary theories, as truth is" ${ }^{14}$. His position is minimalism through and through.

Dorothy Grover, too, maintains that her variant of deflationism, the prosentential theory of truth, is capable of capturing some significant aspects of the correspondence theory. ${ }^{15}$ On the prosentential account, she developed together with John Camp and Nuel Belnap, ${ }^{16}$ there are expressions other than pronouns that can be used anaphorically, i.e., that can substitute for a previous primary expression of the same syntactical form. There are proverbs, proadjectives, and there are prosentences. Whereas pronouns occupy positions nouns occupy, prosentences occupy positions sentences occupy. The central claim of the proponents of this theory is that "that is true" and "it is true" function as prosentences. Thus "It is true that grass is green" can be construed as "Grass is green. That is true". It is important that prosentences are semantically unstructured units. All expressions in which "true" occurs outside of a prosentence have a misleading surface grammar. In the deep structure "true" is not a genuine predicate with a separate meaning. On the contrary, "true" is always a fragment of a prosentence.

A key claim of this account is that prosentences and other proforms can be used as variables of quantification, as well as they can be used to substitute for an antecedent. "Everything Bill says is true", for example, is construed as "For each proposition, if Bill says that it is true, then it is true." This, very roughly, is the prosentential account of the role of the truth predicate in generalizations. The prosentential theory is similar to the disquotational theories in that both claim that the special usefulness of the truth predicate consists in providing us with certain kinds of expressibiliy -

\footnotetext{
${ }^{14}$ Ibid., 125.

15 Grover 1992, 6-9, 29-34.

${ }^{16}$ Grover, Camp and Belnap 1975.
} 
making available generalizations with respect to sentence positions. But, as we have seen, their analyses differ in certain formal respects.

Grover wants to do justice to some important aspects of the correspondence theory. Since on the prosentential theory all T-sentences are affirmed, Grover thinks she can justifiably say that it is the world that makes our sentences and beliefs true. Further, in contrast to many other deflationists, she acknowledges that there actually are interesting, explanatorily relevant, referential relations between language and the world. Such language-world relations play an essential role in the explanation of our various linguistic activities. Thus, in her estimation reference is a substantive relation. Truth, on the other hand, is neither a substantive relation nor a substantive property. Grover, too, emphatically dismisses the idea of explaining truth in terms of reference or satisfaction. Rather, she argues for keeping the issue of truth separate from the issue of reference, and warns urgently against the attempt to incorporate relations between linguistic expressions and extralinguistic entities into the account of truth. Truth talk can be explicated without appeal to a semantical theory that explains how names and predicates refer to things, properties and relations.

The view, then, that a theory of truth is already a correspondence theory because all T-sentences follow from it, is untenable. Thus, the acceptance of the equivalence schema $\mathrm{T}$ or of an analogous propositional equivalence schema is not a sufficient condition for an authentic correspondence theory of truth. For Quine, Horwich, Grover and many other deflationists endorse the equivalences $\mathrm{T}$, but renounce vigorously the possibility of developing a full-blooded correspondence theory. Moreover, many correspondence theorists, such as Wilfrid Sellars, for example ${ }^{17}$ maintain that the equivalences $\mathrm{T}$ are philosophically neutral and that, therefore, we are in need of a richer concept of truth than that the T-sentences are supplying us with. Sellars believes he can find such a richer concept in a picture theory. My suggestion, on the other hand, is that a correspondence theory is one that explains truth in terms of reference or satisfaction. According to this characterization, Tarski's theory is a correspondence theory, the various versions of deflationism, however, are not. Surely, against the background of a referential explication of truth, the T-sentences turn out to be correspondence theoretically interpretable. But the affirmation of the T-sentences alone cannot transform a theory of truth into a genuine correspondence theory.

\footnotetext{
17 Sellars 1963, 197-224.
} 
We have identified an important difference between Tarski's approach and that of modern deflationists or minimalists. Tarski thought of his theory of truth as an elaboration of the classical correspondence notion. The heart of his theory is the definition of truth in terms of satisfaction. Truth consists in, and is explained in terms of, a relation between language and aspects of external reality. It is just this central component of his theory which is rejected by modern deflationism.

Of course, Tarski's theory is not the last word. While some philosophers, for example Popper 1935, indeed claim that Tarski succeeded in rehabilitating the correspondence theory, others take a more pessimistic view. Hartry Field objected that Tarski did not accomplish the aim he set himself, the aim to supply a definition that would satisfy the demands of physicalism. If, so Field argued, truth is defined in terms of satisfaction and reference, the problem still remains, to explain satisfaction and reference. Here we must go beyond Tarski 's merely list-like definitions. Field hopes that the causal-historical theories of reference along the lines suggested by Saul Kripke, Hilary Putnam and Keith Donnellan might yield a plausible analysis. Others, such as Davidson and John McDowell, questioned Field's assumption that the language-world relations at the level of whole sentences are to be derived from language-world relations at the level of the primitive terms of the language. ${ }^{18}$ On their view, a theory of reference is not needed. But these interesting topics, which I have dealt with elsewhere, ${ }^{19}$ cannot be discussed here.

\section{References}

Ayer, A. J., 1936, Language, Truth and Logic, London.

Davidson, D., 1984, Inquiries into Truth and Interpretation, Oxford.

__ , "The structure and content of truth", The Journal of Philosophy 87, 279-328.

Donnellan, K., 1972, "Proper names and identifying descriptions", in D. Davidson \& G. Harman (eds.), Semantics of Natural Language, Dordrecht, 356-379.

Field, H., 1972, "Tarski's theory of truth", The Journal of Philosophy 69, 347-375.

—_, 1984, "Quine and the correspondence theory", Philosophical Review 83, $200-228$.

\footnotetext{
18 Davidson 1984, 130-140; McDowell 1978.

19 Schantz 1996.
} 
Frege, G., 1892, "Über Sinn und Bedeutung", Zeitschrift für Philosophie und Philosophische Kritik 100, 25-50.

Grover, D. L., J. L. Camp Jr., N. D. Belnap Jr., 1975, "A prosentential theory of truth", Philosophical Studies 27, 73-125.

—, 1992, A Prosentential Theory of Truth, Princeton.

Horwich, P., 1990, Truth, Oxford.

Kripke, S., 1972, "Naming and Necessity", in D. Davidson \& G. Harman (eds.), Semantics of Natural Language, Dordrecht, 253-355, 763-769.

Leeds, S., 1978, "Theories of reference and truth", Erkenntnis 13, 111-129.

McDowell, J., 1978, "Physicalism and primitive denotation: Field on Tarski", Erkenntnis 13, 131-152.

Popper, K., 1935, Logik der Forschung, Wien.

Putnam, H., 1975, "The meaning of 'meaning,", in H. Putnam, Mind, Language and Reality: Philosophical Papers, vol. 2, Cambridge, 215-271.

Quine, W. V. O., 1970, Philosophy of Logic, Englewood Cliffs.

—., 1987, Quiddities: An Intermittently Philosophical Dictionary, Cambridge, MA.

— 1990, Pursuit of Truth, Cambridge, MA.

Ramsey, F.P., 1927, "Facts and propositions", Proceedings of the Aristotelian Society, Suppl. vol. 7, 153-171.

Rorty, R., 1986, "Pragmatism, Davidson and truth", in E. LePore (ed.), Truth and Interpretation. Perspectives on the Philosophy of Donald Davidson, Oxford, $333-355$.

Schantz, R., 1996, Wahrheit, Referenz und Realismus. Eine Studie zur Sprachphilosophie und Metaphysik, Berlin \& New York.

Sellars, W., 1963, Science, Perception and Reality, London.

Soames, S., 1984, "What is a theory of truth?", The Journal of Philosophy 81, 411-429.

Strawson, P. F., 1949, "Truth", Analysis 9, 83-97.

Tarski, A., 1935, "Der Wahrheitsbegriff in den formalisierten Sprachen", Studia Philosophica 1, 261-405. English translation: "The concept of truth in formalized languages" in Tarski 1956a, 152-278.

— 1944 , "The semantic conception of truth and the foundations of semantics", Philosophy and Phenomenological Research 4, 341-375.

—. 1956a , Logic, Semantics, Metamathematics, 2d ed., J. Corcoran (ed.), translated by J. H. Woodger, Indianapolis 1983. 
— _ 1956b, "The establishment of scientific semantics", in Tarski 1956a, 401-408.

_, 1969, "Truth and proof", Scientific American 220, H., 6, 63-77.

Williams, M., 1986, "Do we (epistemologists) need a theory of truth?", Philosophical Topics 4, 223-242.

RichaRd Schantz

Institut für Philosophie

Freie Universität Berlin

Habelschwerdter Allee 30

D-14195 Berlin 